\title{
Cellular Delivery of Locked Nucleic Acids (LNAs)
}

This unit describes the introduction of locked nucleic acid (LNA) oligomers (Fig. 4.13.1; Koshkin et al., 1998; Obika et al., 1998; Wang et al., 1999; reviewed in Braasch and Corey, 2001) into cells. It is intended to extend the discussion of the synthesis and characterization of LNA that is found in UNIT 4.12.

\section{INTRODUCTION OF LNA OLIGOMERS INTO CELLS}

As is the case for most other types of oligonucleotide, there is little reason to believe that LNA oligomers will be able to spontaneously enter most types of cultured cells and locate a cellular target. Since LNAs possess a negatively charged backbone, one simple method for promoting uptake is the use of cationic lipid. A step-wise sample procedure for a 48-well plate format is given below and a schematic summary is provided in Figure 4.13.2.

NOTE: The conditions required for successful transfections will vary from one cell line to the next. It is impossible to predict which combination of lipid and oligonucleotide will be most effective; this must be determined empirically for each cell line.

\section{Materials}

Cells grown to confluence in $75-\mathrm{cm}^{2}$ tissue culture flasks

Complete growth medium (see recipe)

$100 \mu$ M LNA stock solution (see Support Protocol 1)

Opti-MEM I (Invitrogen Life Technologies; reduced-serum medium, containing

L-glutamine and no phenol red)

LipofectAMINE (Invitrogen Life Technologies)

48-well tissue culture plate (Costar)

Repeating pipettor (e.g., Eppendorf)

12.5-mL Combitips (Eppendorf)

$65^{\circ}$ and $37^{\circ} \mathrm{C}$ water baths or a thermal cycler

$12 \times 75-\mathrm{mm}$ round-bottom tubes

$37^{\circ} \mathrm{C}, 5 \% \mathrm{CO}_{2}$ incubator

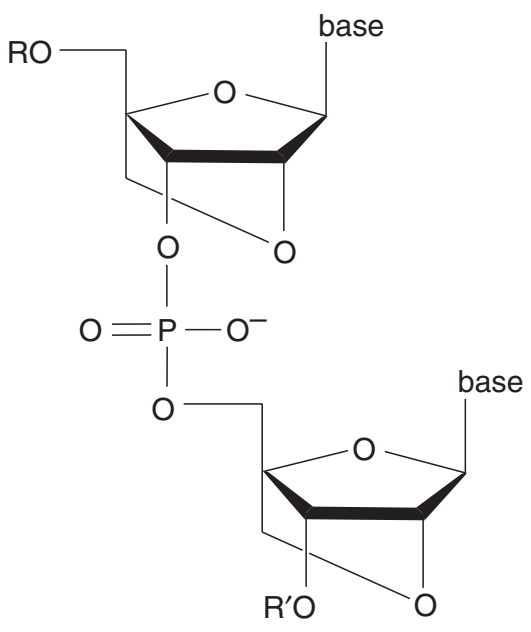

Figure 4.13.1 Structure of LNA.

Contributed by Dwaine A. Braasch and David R. Corey

Current Protocols in Nucleic Acid Chemistry (2002) 4.13.1-4.13.9

Copyright $\odot 2002$ by John Wiley \& Sons, Inc.

$B A S I C$

PROTOCOL
Synthesis of Modified

Oligonucleotides and Conjugates

\subsection{1}

Supplement 9 
Additional reagents and equipment for trypsinizing and counting cells (e.g., $C P M B$ APPENDIX $3 F$ )

NOTE: LipofectAMINE and Opti-MEM I are important to the success of the experiment and should not be substituted.

\section{Prepare cells}

1. Beginning with a $75-\mathrm{cm}^{2}$ tissue culture flask of cells grown to confluence, trypsinize the cells according to standard procedures (e.g., CPMB APPENDIX $3 F$ ).

The total number of cells (and thus the number of flasks) will depend on the number of LNAs being transfected. For transfection of a single LNA, 33,000 to 39,000 cells are needed (11,000 to 13,000 cells per well at three different concentrations of LNA-LipofectAMINE complex).

2. Suspend the cells in fresh complete growth medium.

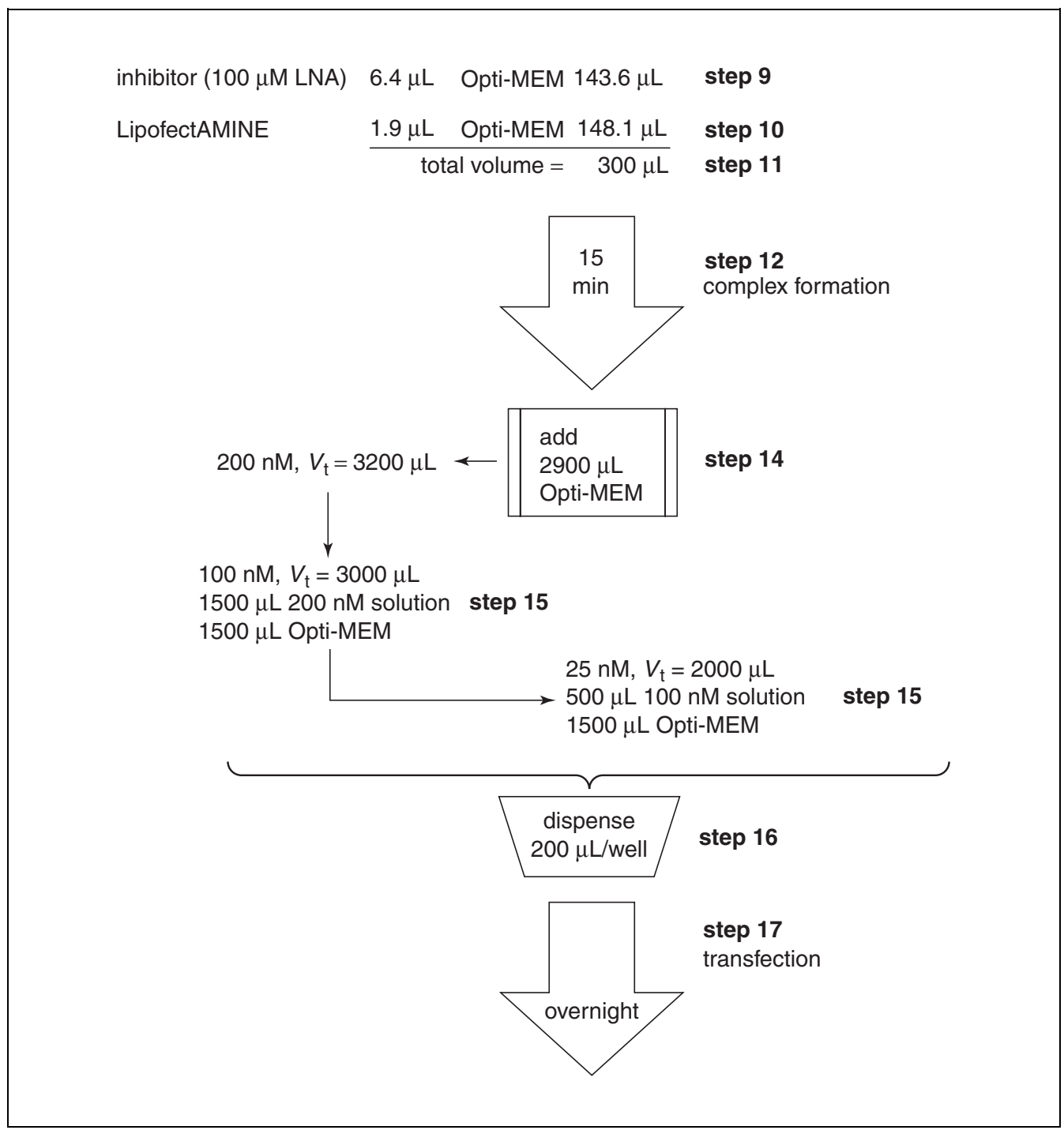

Cellular Delivery of Locked Nucleic Acids (LNAs)

Figure 4.13.2 Preparation of LipofectAMINE-LNA complexes for cellular transfection, including subsequent dilutions of stock complexes. $V_{\mathrm{t}}=$ total volume. Volumes are sufficient for dispensing six replicates and have been optimized for COS-7 cells. 
3. Draw up the entire volume of cell suspension into a 10-mL pipet and dispense back into the flask with the tip of the pipet pressed lightly against the bottom of the flask.

Aggregates of cells will be disrupted, yielding a single-cell suspension that gives more accurate cell counts.

4. Perform a cell count in triplicate using a Coulter counter or hemacytometer (e.g., CPMB APPENDIX $3 F$ ) and average the results.

5. Prepare cell suspension in complete growth medium at a density of 44,000 to 52,000 cells $/ \mathrm{mL}$.

6. Plate cells 4 to $6 \mathrm{hr}$ prior to transfection. For each LNA to be transfected, plate 250 $\mu \mathrm{L}$ cell suspension (11,000 to 13,000 cells) in three wells of a 48 -well tissue culture plate.

For accuracy with larger numbers of LNAs, use a repeating pipettor and a 12.5-mL Combitip.

7. Replace cover on plate and disperse cells evenly within the wells by sliding the plate back and forth, gently bumping it against the front lip of a laminar flow hood work surface. Keep cells 4 to $6 \mathrm{hr}$ at $37^{\circ} \mathrm{C}$ in a $5 \% \mathrm{CO}_{2}$ incubator for cells to attach to the surface.

\section{Prepare LNA-LipofectAMINE complexes}

8. Warm $100 \mu \mathrm{M}$ LNA stock solution $5 \mathrm{~min}$ at $65^{\circ} \mathrm{C}$ for a 15 -mer or $95^{\circ} \mathrm{C}$ for a 25 -mer to disrupt aggregates, and then maintain at $37^{\circ} \mathrm{C}$ until transfection. Also warm Opti-MEM I to $37^{\circ} \mathrm{C}$.

9. In a $12 \times 75-\mathrm{mm}$ round-bottom tube, dilute $6.4 \mu \mathrm{L}$ of $100 \mu \mathrm{M}$ LNA with $143.6 \mu \mathrm{L}$ Opti-MEM I.

10. In a separate $12 \times 75-\mathrm{mm}$ round-bottom tube, dilute $1.9 \mu \mathrm{L}$ LipofectAMINE with 148.1 1 L Opti-MEM I.

This solution can be scaled up in a single tube depending on how many unique conditions are being tested. If, for example, five inhibitors (LNAs) are to be tested, then it would be advantageous to prepare sufficient lipid mix for seven conditions.

11. Add $150 \mu \mathrm{L}$ LipofectAMINE from step 10 to each LNA in step 9 (total $300 \mu \mathrm{L}$ ) and tap the tube briskly 15 times to mix the reagents and initiate the formation of LNA-LipofectAMINE complexes.

12. Allow the tube to sit $15 \mathrm{~min}$ at room temperature in the dark.

Opti-MEM I is light sensitive.

\section{Transfect cells}

13. While waiting for complexes to form, aspirate off the complete growth medium in each well of the tissue culture plate and replace with $250 \mu \mathrm{L}$ Opti-MEM I per well. Also set up two tubes for a dilution series of LNA-LipofectAMINE complexes and add $1.5 \mathrm{~mL}$ Opti-MEM I to each.

14. When the incubation (step 12) is complete, add $2.9 \mathrm{~mL}$ Opti-MEM I to the LNALipofectAMINE complexes and mix well.

This gives $3.2 \mathrm{~mL}$ at $200 \mathrm{nM}$ LNA for the starting concentration for the serial dilution. The authors typically use $200 \mathrm{nM}$ or $500 \mathrm{nM}$ as the starting concentration.

Synthesis of Modified

Oligonucleotides and Conjugates

\subsection{3}


SUPPORT PROTOCOL 1

Cellular Delivery of Locked Nucleic Acids (LNAs)

4.13.4
15. Transfer $1.5 \mathrm{~mL}$ stock to one of the tubes in step 13 (final $3 \mathrm{~mL}$ at $100 \mathrm{nM}$ ) and mix well. Transfer $500 \mu \mathrm{L}$ of this solution to the second tube (final $2 \mathrm{~mL}$ at $25 \mathrm{mM}$ ) and mix well.

If $500 \mathrm{nM}$ is used as the starting concentration, a $200 \mathrm{nM}$ dilution should be included.

16. Aspirate the Opti-MEM I wash from the cells and immediately dispense $200 \mu \mathrm{L}$ of each LNA-LipofectAMINE dilution to the appropriate wells, working backward through the dilution scheme for a given LNA.

17. Allow cells to incubate overnight at $37^{\circ} \mathrm{C}$.

18. Aspirate off transfection solution and replace with $250 \mu \mathrm{L}$ complete growth medium.

19. Incubate $>24 \mathrm{hr}$ at $37^{\circ} \mathrm{C}$ prior to conducting an assay for the effects of the LNA.

When developing a protocol for delivering LNAs into cells, it is useful to obtain a fluorophore-labeled LNA. Delivery of the LNA can be visualized by microscopy, facilitating the evaluation and subsequent optimization of delivery conditions.

\section{PREPARATION OF LNA OLIGOMER STOCK SOLUTIONS}

LNA oligomers arrive lyophilized and should be handled like DNA or RNA oligomers.

\section{Materials}

Locked nucleic acid oligomers (LNAs; Proligo)

DNase/RNase-free water (Life Technologies)

Spectrophotometer

1. If LNAs have been refrigerated, allow them to equilibrate to room temperature.

2. Centrifuge the samples $2 \mathrm{~min}$ at $14,000 \times g$, room temperature, to collect LNA at the bottom of the tube.

3. Add DNase/RNase-free water to give a stock solution of $\sim 1 \mathrm{mM}$. Allow the oligomer to sit undisturbed for 10 to $15 \mathrm{~min}$ at room temperature.

The estimated concentration is based on the volume, on the mass reported by the manufacturer, and on the molecular weight of a given LNA.

4. Vortex in 5-sec bursts several times. Heat to $65^{\circ} \mathrm{C}$ for up to $15 \mathrm{~min}$ and cool to room temperature.

5. Allow tubes to sit undisturbed for $5 \mathrm{~min}$, room temperature.

6. Centrifuge $2 \mathrm{~min}$ at $14,000 \times g$, room temperature, to pellet any remaining undissolved material.

Observe the tube contents carefully at this point, as occasionally there are insoluble materials that can interfere with cellular assays. It is best not to proceed with cellular assays if an LNA exhibits this behavior unless one has significant experience in desalting and purifying oligomers. Consult the manufacturer if solubility properties are not satisfactory.

7. Remove a $1-\mu \mathrm{L}$ aliquot and dilute it with $144 \mu \mathrm{L}$ distilled water. Ascertain the absorbance at $260 \mathrm{~nm}$.

8. Calculate the concentration of the LNA using the following equation, where $33 \mathrm{ng} / \mu \mathrm{L}$ is the extinction coefficient of the LNA and 145 is the dilution factor:

$$
c(\mathrm{mM})=\left(A_{260} \times 33 \mathrm{ng} / \mu \mathrm{L} \times 145\right) / \mathrm{mol} \text {. wt. of LNA }
$$


The value $33 \mathrm{ng} / \mu \mathrm{L}$ assumes an average extinction coefficient based on an equal population of all bases. If the LNA contains a preponderance of one or two bases, the equation can be modified (e.g., see CPMB APPENDIX 3D) using the appropriate extinction coefficients. The extinction coefficients of the LNA nucleotide analogs are not available to the authors, but it may be reasonable to assume that they are the same as for DNA nucleotides (Proligo, pers. comm.).

9. Adjust concentration to $100 \mu \mathrm{M}$ and store the stock solution for up to 1 year at $4{ }^{\circ} \mathrm{C}$.

\section{DETERMINATION OF $T_{m}$ FOR LNA OLIGOMERS}

To understand the potential for LNA oligonucleotides to recognize intracellular targets, it is useful to determine $T_{\mathrm{m}}$ values for LNAs with complementary RNA or DNA oligomers.

\section{Materials}

LNA oligonucleotides

DNA or RNA oligomers

$10 \times \mathrm{Ca}^{2+}$ - and $\mathrm{Mg}^{2+}$-free phosphate-buffered saline (CMF-PBS; Invitrogen Life

Technologies or see recipe)

$0.1 \mathrm{M} \mathrm{Na}_{2} \mathrm{HPO}_{4}$ buffer, $\mathrm{pH} 7.5$ (Fisher)

Mineral oil (Sigma)

Stoppered cuvette (1-cm pathlength and 1.5-cm Z dimension; Spectrosil Far UV

Quartz, Uvonic Instruments)

Spectrophotometer with temperature-controlled cuvette holder

1. Calculate the concentration of each of the single-stranded components (LNA and either DNA or RNA).

The concentration of LNAs can be determined from the $A_{260}$ value of a diluted aliquot (see Support Protocol 1, step 8).

It is sometimes useful to heat the LNAs to $65^{\circ} \mathrm{C}$ or higher, depending on the oligomer length and the number of LNA bases, to break up intra- and intermolecular hydrogen bonding and aggregation. When preparing oligonucleotide pairs for $T_{m}$ analysis or tranfection, it is prudent to heat the samples and ensure that the concentrations are accurate.

2. Prepare a small volume ( 20 to $30 \mu \mathrm{L})$ of $100 \mu \mathrm{M}$ heteroduplex nucleic acid in a solution containing $2.5 \times$ CMF-PBS final concentration.

3. Dilute a $5-\mu \mathrm{L}$ aliquot of the $100 \mu \mathrm{M}$ heteroduplex mixture with $145 \mu \mathrm{L}$ of $0.1 \mathrm{M}$ $\mathrm{Na}_{2} \mathrm{HPO}_{4}$ buffer, $\mathrm{pH} 7.5$, in a 1-cm-pathlength stoppered cuvette.

4. Overlay this solution with $145 \mu \mathrm{L}$ mineral oil to minimize evaporation.

5. Monitor the change in the absorbance at $260 \mathrm{~nm}$ every $5^{\circ} \mathrm{C}$ as the temperature is ramped from $100^{\circ}$ to $12^{\circ} \mathrm{C}$ and also back up to $100^{\circ} \mathrm{C}$.

6. Fit the data collected from these analyses using van't Hoff thermal denaturation/renaturation curve analysis to determine the $T_{\mathrm{m}}$ values from the denaturation and renaturation curves (UNIT 7.3).

It is not uncommon for entirely LNA oligomers with $>11$ bases to possess $T_{m}$ values $>95^{\circ} \mathrm{C}$.

Synthesis of Modified

Oligonucleotides and Conjugates

4.13.5 


\section{REAGENTS AND SOLUTIONS}

Use deionized, distilled water in all recipes and protocol steps. For common stock solutions, see APPENDIX 2A; for suppliers, see SUPPLIERS APPENDIX.

\section{CMF-PBS (Ca ${ }^{2+}$ - and $\mathrm{Mg}^{2+}$-free phosphate-buffered saline), 10×}

$10.4 \mathrm{mM} \mathrm{KH}_{2} \mathrm{PO}_{4}$

$1551.7 \mathrm{mM} \mathrm{NaCl}$

$29.6 \mathrm{mM} \mathrm{Na}{ }_{2} \mathrm{HPO}_{4} \cdot 7 \mathrm{H}_{2} \mathrm{O}, \mathrm{pH} 7.4$

Store up to 1 year at $4^{\circ} \mathrm{C}$

\section{Complete growth medium}

Dulbecco's modified Eagle's medium (DMEM) high-glucose without L-glutamine (e.g., Mediatech Cellgro, Fisher) containing:

$20 \mathrm{mM}$ HEPES buffer, $\mathrm{pH} 7.4$ (cell-culture grade, Sigma)

$10 \%$ (w/v) FBS (Atlanta Biologicals)

$1 \times$ PSF (see recipe)

$0.7 \mathrm{mg} / \mathrm{mL}$ tylosin (Sigma)

$2 \mathrm{mM}$ L-glutamine (Invitrogen Life Technologies)

Store up to 4 months at $4^{\circ} \mathrm{C}$

PSF (penicillin/streptomycin/Fungizone), 100×

10,000 U penicillin

$10 \mathrm{mg}$ streptomycin

$25 \mu \mathrm{g} / \mathrm{mL}$ amphotericin B (e.g., Fungizone, Invitrogen Life Technologies)

Store up to 1 year at $-20^{\circ} \mathrm{C}$

\section{COMMENTARY}

\section{Background Information}

LNAs offer several advantages for nucleic acid recognition (Table 4.13.1), which should encourage investigators to consider their use. Currently, oligonucleotides that contain LNA bases can be obtained commercially from Proligo (http://www.proligo.com). Synthesis is based on phosphoramidite chemistry and employs LNA monomers of A, T, G, and 5-methylC.

The most striking advantage conferred by use of LNA bases is a dramatic increase in the affinity of binding to complementary sequences (Table 4.13.2). A single LNA base can increase the melting temperature $\left(T_{\mathrm{m}}\right)$ of binding by $10^{\circ} \mathrm{C}$, and oligomers that contain several strategically positioned LNA bases can bind with even higher affinity than analogous peptide nucleic acid (PNA) oligomers (Braasch and Elayadi, unpub. observ.). LNA bases are introduced into oligonucleotides by standard synthesis methods (UNIT 4.12), allowing LNA bases to be interspersed among DNA or RNA bases. As a result, important properties such as
Cellular Delivery of Locked Nucleic Acids (LNAs)

4.13.6

Table 4.13.1 Advantages of Locked Nucleic Acids

High affinity hybridization

Synthesized like DNA/RNA

Negatively charged backbone
Tight binding by short LNAs or at high temperatures

Enables ready adaptation of existing synthesizers. Simple to intersperse DNA or RNA bases to modulate $T_{\mathrm{m}}$ values or RNase $\mathrm{H}$ sensitivity.

Good solubility; investigators who work with DNA or RNA will find LNA easy to work with. Ability to incorporate phosphorothioate linkages to improve stability or pharmacokinetic properties. 
Table 4.13.2 Melting Temperature $\left(T_{\mathrm{m}}\right)$ Values for LNAs and LNA-DNA Hybrids

\begin{tabular}{|c|c|c|c|c|c|}
\hline $\mathrm{LNA}$ or LNA-DNA ${ }^{a}$ & $T_{\mathrm{m}}$ & $T_{\mathrm{m}}(\mathrm{ref})^{b}$ & $\Delta T_{\mathrm{m}}$ & $\begin{array}{l}\Delta T_{\mathrm{m}} / \mathrm{LNA} \\
\text { base }\end{array}$ & Reference \\
\hline GTGTTTTGC & 52 & 28 & 24 & 5 & Kumar et al. (1998) \\
\hline$\underline{\text { GTGTCCGAGACGTTG }}$ & 72 & 59 & 13 & 1.5 & Wahlstedt et al. (2000) \\
\hline GTGTCCGAGACGTTG & 83 & 59 & 24 & 3 & Wahlstedt et al. (2000) \\
\hline$\underline{\text { GTGTCCGAGACGTTG }}$ & $>90$ & 59 & $>31$ & 2 & Wahlstedt et al. (2000) \\
\hline $\mathrm{C} \underline{\mathrm{ACT}} \underline{\mathrm{A}} \underline{\mathrm{A}} \underline{\mathrm{CG}}$ & 40 & 29 & 11 & 3.3 & Koshkin et al. (1998) \\
\hline CTGATATGC & 36.8 & 27.2 & 9.6 & 9.6 & Bondensgaard et al. (2000) \\
\hline CTGA $\underline{T A T G C}$ & 51.6 & 27.2 & 24.4 & 8.1 & Bondensgaard et al. (2000) \\
\hline$\underline{\mathrm{A} G G G} \underline{\mathrm{TCG}} \underline{\mathrm{G}} \underline{\mathrm{Te}} \underline{\mathrm{CGGTG}} \underline{\mathrm{T}}$ & $>96$ & 53 & 43 & 3 & Braasch (unpub. observ.) \\
\hline 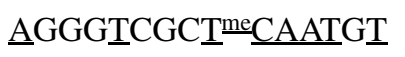 & 83 & $\mathrm{NP}^{c}$ & - & - & Braasch (unpub. observ.) \\
\hline$\underline{\text { me }} \underline{\text { AGTTAGGGTTAG }}$ & 81 & 50 & 31 & 3.1 & Braasch (unpub. observ.) \\
\hline$\underline{\text { me }} \underline{\text { AGTTAGAATTAG }}$ & 65 & $\mathrm{NP}^{c}$ & - & - & Braasch (unpub. observ.) \\
\hline$\underline{\text { TAGGGT }}$ & 56 & $\mathrm{ND}^{\mathrm{c}}$ & - & - & Braasch (unpub. observ.) \\
\hline$\underline{\text { TAGGGTTA }}$ & 74 & 22 & 52 & 6.5 & Braasch (unpub. observ.) \\
\hline$\underline{\text { AGGAT }} \underline{\underline{m e}} \underline{\text { CTAGGTGAA }}$ & $>96$ & 53 & 25 & 2.9 & Braasch (unpub. observ.) \\
\hline$\underline{\text { AGGAT }^{\underline{m e}} \underline{\underline{C T A G G}}}$ & 73 & 39 & 34 & 3.4 & Braasch (unpub. observ.) \\
\hline$\underline{\text { AGGAT }} \stackrel{\text { me }}{\underline{C}} \underline{\underline{A G G T G A A}}$ & 59 & 53 & 6 & 0.6 & Braasch (unpub. observ.) \\
\hline
\end{tabular}

$T_{\mathrm{m}}$ or RNase $\mathrm{H}$ activation can be tailored to meet the specifications of individual applications. This combination of high-affinity hybridization with standard synthesis protocols is powerful because it encourages adapting LNAs to existing protocols that use oligonucleotides.

\section{Critical Parameters}

When designing oligonucleotides that are intended to function inside cells, the ability of the oligonucleotides to form duplexes that act as substrates for RNase $\mathrm{H}$ is a primary consideration (Crooke, 1999). RNase $\mathrm{H}$ degrades RNA-DNA hybrids, allowing oligonucleotides that contain DNA to promote the cleavage of mRNA. If antisense inhibition of gene expression is desired, this can be an advantage since the target mRNA is permanently inactivated, and the antisense oligomer can then move on to inactivate additional mRNA molecules. Oligonucleotides that cannot recruit RNase $\mathrm{H}$ (i.e., that do not contain DNA portions) can block the binding of the translation apparatus when targeted to the $5^{\prime}$ terminus of the untranslated region (Baker et al., 1997; Doyle et al., 2001). Oligomers that do not activate RNase $\mathrm{H}$ can also redirect splicing when targeted to splice sites (Kang et al., 1998), but when they are targeted to other mRNA sequences, they are likely to be displaced by the ribosome.

Oligomers that contain only LNA bases activate RNase H poorly (Wahlestedt et al., 2000). However, because LNAs are made using protocols similar to those used for DNA synthesis, it is straightforward to incorporate DNA bases into LNA-DNA chimera. This provides the experimenter with the choice of whether or not to incorporate RNase $\mathrm{H}$ sensitivity into oligonucleotide design by including a contiguous run of at least six DNA bases. If antisense gene inhibition is desired, this strategy may allow a wider range of sequences to be targeted. If simple steric blocking of the RNA target is required, the potential to direct RNase H cleavage is unnecessary and even counterproductive because it might lead to unintentional destruction of nontargeted RNA substrates.

LNA bases confer some increase in the stability of oligomers to degradation by nucleases. However, to achieve maximal stability in animal studies, it is likely that one or two phosphorothioate (PS) linkages will need to be substituted at both the $3^{\prime}$ - and $5^{\prime}$-terminal linkages. As noted above, LNA synthesis is similar to the
Synthesis of Modified Oligonucleotides and Conjugates

4.13.7 
synthesis of DNA or RNA, allowing PS linkages to be added routinely (Kumar et al., 1998). Complete substitution of phosphodiester linkages with PS linkages has also been noted to improve the pharmacokinetic properties of antisense oligonucleotides (Geary et al., 2001). It is reasonable to believe that LNA-containing oligomers will also need to be modified with PS linkages to achieve in vivo efficacy, though animal studies will be necessary to establish if this truly is the case for LNA-containing chimeric oligonucleotides.

The choice of whether or not to exploit the potential for RNase $\mathrm{H}$ activation influences how antisense activity will be examined on a case-by-case basis. LNA oligomers that contain DNA segments that can activate RNase $\mathrm{H}$ will cause RNA to be degraded, allowing efficacy to be judged by northern analysis. LNA oligomers that cannot activate RNase $\mathrm{H}$ can be evaluated by examining the expression of the protein target or by measuring its activity. As with any antisense experiment, use of control oligonucleotides that contain mismatched bases is necessary to support the belief that an effect is specific, i.e., due to binding to the intended mRNA target.

\section{Troubleshooting}

When oligonucleotides are introduced into cells, they may prove to be toxic. This toxicity could be due to successful inhibition of the target gene function. However, toxicity could also be due to (1) binding to one or more nontarget proteins, (2) hybridization to one or more nontarget nucleic acid sequences, or (3) poisoning of the cells by small molecule impurities or endotoxins. The primary consideration is that the observed effects should be consistent with the biology of the system being examined.

If cell death is observed, LNAs can be purified by desalting to remove small molecule contaminants. Alternatively, a fresh synthesis of LNA can be performed to determine if newly made material behaves similarly. Toxicity could also be caused by improper choice of transfection conditions, reagent concentrations, cell line, or lipids. The window between the conditions that produce optimal LNA delivery and those that cause cells to die is likely to be small. Use of fluorophore-labeled LNAs provides a convenient method for evaluating the success of a given protocol. The authors have also observed that some syntheses of LNAs are relatively insoluble. If this occurs, the experimenter should consult with the manufacturer.

\section{Anticipated Results}

There are many effective antisense oligonucleotides that do not contain LNA bases. Why use LNA? Why not stay with standard oligonucleotide designs? The use of LNAs is only three years old, and there are no definitive answers to these questions. However, it is reasonable to speculate that the ability of LNA bases to dramatically improve the affinity of binding might increase the potency, specificity, and predictability of antisense action. The resulting increase in efficacy would allow "knock down" phenotypes to be generated more easily, and the fact that LNA bases can be easily incorporated into oligonucleotides allows this hypothesis to be readily tested.

Microscopic examination of the delivery of a fluorophore-labeled LNA is a useful demonstration that transfection conditions are promoting LNA uptake by cells. In the authors' experience, micrographs show that LNA is distributed throughout the cytoplasm and nucleus, with some punctate staining indicating areas of high concentration.

\section{Time Considerations}

LNAs normally can be obtained within 2 weeks of placing an order with Proligo. LNAs should completely dissolve in water within 20 min. Quantification of LNA concentration by UV spectrophotometry and determination of a $T_{\mathrm{m}}$ value should take $\sim 2 \mathrm{hr}$. Transfection of LNA into cells should require an additional 2 to $4 \mathrm{hr}$. The time required for observation of a phenotype will vary from hours to days, depending on the gene being targeted.

\section{LITERATURE CITED}

Baker, B.F., Lot, S.S., Condon, T.P., Cheng-Flournoy, S., Lesnik, E.A., Sasmor, H.M., and Bennett, C.F. 1997. 2'-O-(2-Methoxy)ethyl-modified anti-intercellular adhesion molecule 1 (ICAM-1) oligonucleotides selectively increase the ICAM-1 mRNA level and inhibit formation of the ICAM-1 translation initiation complex in human umbilical vein endothelial cells. J. Biol. Chem. 272:11994-12000.

Bondensgaard, K., Petersen, M., Singh, S.K., Rajwanshi, V.K., Kumar, R., Wengel, J., and Jacobsen, J.P. 2000. Structural studies of LNA:RNA duplexes by NMR: Conformations and RNase $\mathrm{H}$ activity. Chem. Eur. J. 6:2687-2695.

Braasch, D.A. and Corey, D.R. 2001. Locked nucleic acids: Fine-tuning nucleic acid recognition. Chem. Biol. 8:1-7.

Crooke, S.T. 1999. Molecular mechanisms of antisense drugs: Human RNase H. Antisense Nucl. Acid Drug Devel. 9:377-379.

\section{Cellular Delivery Locked Nucleic 4.13.8}

Supplement 8 
Doyle, D.F., Braasch, D.A., Simmons, C.G., Janowski, B.A., and Corey, D.R. 2001. Inhibition of gene expression inside cells by peptide nucleic acids: Effect of mRNA target sequence, mismatched bases, and PNA length. Biochemistry 40:53-64.

Geary, R.S., Yu, R.Z., and Levin, A.A. 2001. Pharmacokinetics of phosphorothioate antisense oligonucleotides. Curr. Opin. Investigational New Drugs 2:562-573.

Kang, S.H., Cho, M.J., and Kole, R. 1998. Up-regulation of luciferase gene expression with antisense oligonucleotides-Implications and applications in functional assay developments. Biochemistry 37:6235-6239.

Koshkin, A.A., Singh, S.K., Nielsen, P., Rajwanshi, V.K., Kumar, R., Meldgaard, M., Olsen, C.E., and Wengel, J. 1998. LNA (locked nucleic acids): Synthesis of the adenine, cytosine, guanine, 5-methylcytosine, thymine, and uracil bicyclonucleoside monomers, oligomerisation and unprecedented nucleic acid recognition. Tetrahedon 54:3607-3630.

Kumar, R., Singh, S., Koshkin, A.A., Rajwanshi, V.K., Meldgaard, M. and Wengel, J. 1998. The first analogues of LNA (locked nucleic acids): Phosphorothioate-LNA and 2'-thio-LNA. Bioorg. Med. Chem. Lett. 8:2219-2222.
Obika, S., Nanbu, D., Hari, Y., Andoh, J., Morio, K., Doi, T., and Imanishi, T. 1998. Stability and structural features of the duplexes containing the nucleoside analogues with a fixed $N$-type conformation, 2'-O,4'-C-methyleneribonucleosides. Tetrahedron Lett. 39:5401-5404.

Wahlestedt, C., Salmi, P., Good, L., Kela, J., Johnsson, T., Hokfelt, T., Broberger, C., Porreca, F., Lai, J., Ren, K., Ossipov, M., Koshkin, A., Jakobsen, N., Skouv, J., Oerum, H., Havsteen Jacobsen, M., and Wengel, J. 2000. Potent and nontoxic antisense oligonucleotides containing locked nucleic acids. Proc. Natl. Acad. Sci. U.S.A. 97:5633-5638.

Wang, G., Gunic, E., Girardet, J-L., and Stoisavljevic, V. 1999. Conformationally locked nucleosides. Synthesis and hybridization properties of oligodeoxynucleotides containing $2^{\prime} 4^{\prime}-\mathrm{C}$ bridged 2'-deoxynucleosides. Bioorg. Med. Chem. Lett. 9:1147-1150.

Contributed by Dwaine A. Braasch and David R. Corey

University of Texas Southwestern Medical

Center at Dallas

Dallas, Texas
Synthesis of Modified Oligonucleotides and Conjugates

\subsection{9}

Supplement 8 